\title{
Regional TFP disparities in China(1978-2012)
}

\author{
Kaiyao $\mathrm{Wu}^{1,2, \mathrm{a}^{*}}$, Qing Shen ${ }^{2, \mathrm{~b}}$, Zhiwei Zhang ${ }^{2, \mathrm{c}}$ \\ ${ }^{1}$ Antai College of Economics \& Management, Shanghai JiaoTong University, Shanghai, \\ 200052,China; \\ ${ }^{2}$ School of Statistics and mathematics, Shanghai Finance University, Shanghai, 201209, China \\ akaiwencn@163.com, b441490250@qq.com, ${ }^{\text {c } 852696434 @ q q . c o m ~}$
}

Keywords: TFP, DEA, Malmquist Index, Regional disparities

Abstract: The paper focuses on regional disparities of economic development in 1978 to 2012 in China. It uses DEA to compute regional Malmquist index for comparing purpose, and investigates convergence of regional TFP disparities. Our study suggests that regional differences in TFP tend to expand in the research period.

\section{Introduction}

Since 1978, the beginning of Chinese economic reform , China's economy and society in all regions have made great progress. However, there was a big difference based on educational and cultural level, capital investment level and labor level, so that there was a big gap of economic development. Especially from 1991, the gap continued to increase, increasingly becoming a hot topic of the academic community. If the disparity increased, it would be not conducive to the stability of the regional development.

Many scholars had already studied the problem of unbalanced economic development from various aspects and angles, such as Qiang Liu (2001) found the regional characteristics and stage characteristics of China's economic development. Chengliang Zhu (2009) used a logarithmic Cobb - Douglas function to explore the reason of disparities in economic development in China. In this paper, we research the topic from the perspective of regional TFP.

TFP refers to "the efficiency of productive activities within a certain time " , which measures unit total output of unit total investment, is an indicator for productivity. The margin part that production growth exceeds the growth of factor increased is called TFP. Scientific progress, positive creation, and professional advancement are the main way to promote TFP improvement, in the current background of innovation and economic growth mode transition in China, studying regional disparities of TFP has important practical significance. Jun Zhang (2003), Guohua Peng (2005), Xiang Fu (2007), Jinming Zhu (2008), Chengliang Zhu (2009) has studied TFP, and provided methods to refer for this paper.

\section{model and data}

We use the Malmquist index model to calculate TFP. The advantages is that this model does not need to assume concrete form of the function, in order to prevent inappropriate problems in 
establishing function. Malmquist index can be further decomposed into technical efficiency index and technological progress index.

The formula of Malmquist productivity index is:

$$
M_{0}\left(X^{t+1}, Y^{t+1}, X^{t}, Y^{t+1}\right)=\left[\left(\frac{D_{0}^{t}\left(X^{t+1}, Y^{t+1}\right)}{D_{0}^{t}\left(X^{t}, Y^{t}\right)}\right)\left(\frac{D_{0}^{t+1}\left(X^{t+1}, Y^{t+1}\right)}{D_{0}^{t+1}\left(X^{t}, Y^{t}\right)}\right]^{1 / 2}\right.
$$

In the above, $D_{0}^{t}\left(X^{t}, Y^{t}\right)$ is Output Distance Function, Fare ( 2001$)$ decomposed it into technological progress change(TC) and technical efficiency change (EC). When the Malmquist productivity index is greater than 1 , then the total factor productivity is positive growth, when less than 1, it indicates a negative growth of total factor productivity. From (1), we can obtained:

$$
M_{0}\left(X^{t+1}, Y^{t+1}, X^{t}, Y^{t}\right)=\frac{D_{0}^{t+1}\left(X^{t+1}, Y^{t+1}\right)}{D_{0}^{t}\left(X^{t}, Y^{t}\right)}\left[\left(\frac{D_{0}^{t}\left(X^{t+1}, Y^{t+1}\right)}{D_{0}^{t+1}\left(X^{t+1}, Y^{t+1}\right)}\right)\left(\frac{D_{0}^{t}\left(X^{t}, Y^{t}\right)}{D_{0}^{t+1}\left(X^{t}, Y^{t}\right)}\right)\right]^{1 / 2}
$$

So we can define technical efficiency change and technological progress change:

$$
\begin{aligned}
& E C=\frac{D_{0}^{t+1}\left(X^{t+1}, Y^{t+1}\right)}{D_{0}^{t}\left(X^{t}, Y^{t}\right)} \\
& T C=\left[\left(\frac{D_{0}^{t}\left(X^{t+1}, Y^{t+1}\right)}{D_{0}^{t+1}\left(X^{t}+1\left(X^{t+1}, Y^{t+1}\right)\right)}\right) \frac{D_{0}^{t}\left(x^{t}, y^{t}\right)}{D^{t+1}\left(X^{t}, Y^{t}\right)}\right]^{1 / 2}
\end{aligned}
$$

And then we can get Malmquist TFP index decomposition formula:

$$
M_{0}\left(X^{t+1}, Y^{t+1}, X^{t}, Y^{t}\right)=E C * T C
$$

We then take the DEA technique to calculate the Malmquist productivity index. This technique is applicable to "economies of scale" of "production department" that have multiple inputs and multiple outputs.

Since we focus on economic development of all regions in three decades after Chinese economic reform, therefore, this article take the raw data of "new China's statistics compilation in fifty-five years," "China Statistical Yearbook 2013", as well as related data of provinces economic growth that collected by Mingxing Liu's from 1970 to 1999. Tibet and Hainan are not included due to incomplete data. Taking into account geographical factors, the data of Chongqing is incorporated in Sichuan Province. Therefore the data involves a total of 28 Chinese provinces and cities. The data has been taken to the following process:

Actual GDP Make GDP output indicators for selected provinces and make 1978 as the base period in terms of real value.

Capital stock Estimates capital stock, based on China Statistical Yearbook (2013) and existing capital stock data from 1978 to 2012,using the same method as Jun Zhang (2004),"perpetual inventory method". The way is $K_{i, t}=I_{i, t}+\left(1-\delta_{i}\right) K_{i, t+1}$, in the formula, $K_{i, t}$ is t year investment 
of i province, $\delta_{i}$ is fixed assets depreciation rate of i province. Then the values are transformed, taking 1978 as the base period.

Labor In terms of sustainable development, we need to know effective output per unit time for very labor, that is, their work efficiency. But the data is difficult to collection and processing, so we use the amount of labor in all provinces of the country instead.

\section{Empirical results}

\section{Changes in TFP s and analysis}

Use DEAP software, according to CRS output-oriented model, calculate total factor productivity (TPF), technical progress (TC) and technical efficiency (EC) of various provinces. Due to national policy, the time is divided into 1978 to 1990 and 1991 to 2012. And because various reasons (GDP gap, differences in industrial structure, employment structure, people's living standards, urbanization, foreign trade, education and scientific research, and many other aspects), This article divides provinces into three regions for aggregation research. 
Table 1 Changes in Provinces of China TFP, EC, TC

\begin{tabular}{|c|c|c|c|c|c|c|c|c|c|}
\hline & \multicolumn{3}{|c|}{ 1978 2012 } & \multicolumn{3}{|c|}{ 1978 1990 } & \multicolumn{3}{|c|}{$1991 \sim 2012$} \\
\hline Province & $\mathrm{EC}$ & $\mathrm{TC}$ & TFP & $\mathrm{EC}$ & $\mathrm{TC}$ & TFP & $\mathrm{EC}$ & $\mathrm{TC}$ & TFP \\
\hline Beijing & 0.980 & 1.062 & 1.042 & 0.988 & 1.008 & 0.977 & 0.973 & 1.112 & 1.073 \\
\hline Tianjin & 1.013 & 1.025 & 1.036 & 1.009 & 1.003 & 1.012 & 1.025 & 1.035 & 1.058 \\
\hline Hebei & 1.010 & 1.056 & 1.066 & 1.009 & 1.035 & 1.044 & 1.012 & 1.066 & 1.089 \\
\hline Liaoning & 1.001 & 1.039 & 1.039 & 1.000 & 1.027 & 1.027 & 1.001 & 1.051 & 1.043 \\
\hline Shanghai & 1.000 & 1.052 & 1.049 & 1.000 & 1.025 & 1.025 & 1.006 & 1.066 & 1.061 \\
\hline Jiangsu & 1.023 & 1.055 & 1.079 & 1.027 & 1.039 & 1.067 & 1.021 & 1.068 & 1.088 \\
\hline Zhejiang & 1.023 & 1.056 & 1.080 & 1.035 & 1.039 & 1.076 & 1.011 & 1.073 & 1.072 \\
\hline Fujian & 1.026 & 1.057 & 1.082 & 1.039 & 1.036 & 1.077 & 1.011 & 1.079 & 1.087 \\
\hline Shandong & 1.017 & 1.047 & 1.065 & 1.033 & 1.026 & 1.059 & 1.005 & 1.064 & 1.065 \\
\hline Guangdong & 1.025 & 1.054 & 1.076 & 1.043 & 1.034 & 1.079 & 1.009 & 1.074 & 1.072 \\
\hline Shanxi & 1.002 & 1.048 & 1.050 & 1.014 & 1.025 & 1.040 & 0.995 & 1.072 & 1.060 \\
\hline Jilin & 1.004 & 1.055 & 1.059 & 1.002 & 1.031 & 1.033 & 1.003 & 1.073 & 1.084 \\
\hline $\begin{array}{c}\text { Heilongjian } \\
\mathrm{g}\end{array}$ & 0.993 & 1.049 & 1.041 & 0.996 & 1.020 & 1.016 & 0.981 & 1.074 & 1.066 \\
\hline Anhui & 1.007 & 1.024 & 1.031 & 0.990 & 1.024 & 1.014 & 1.023 & 1.025 & 1.054 \\
\hline Jiangxi & 1.003 & 1.034 & 1.042 & 1.008 & 1.033 & 1.041 & 1.001 & 1.038 & 1.041 \\
\hline Henan & 1.007 & 1.057 & 1.064 & 1.021 & 1.034 & 1.056 & 1.002 & 1.075 & 1.079 \\
\hline Hubei & 1.018 & 1.053 & 1.069 & 1.026 & 1.039 & 1.066 & 1.009 & 1.070 & 1.075 \\
\hline Hunan & 1.002 & 1.059 & 1.061 & 1.008 & 1.035 & 1.043 & 1.005 & 1.082 & 1.073 \\
\hline $\begin{array}{c}\text { Nei } \\
\text { Menggu }\end{array}$ & 1.008 & 1.051 & 1.058 & 1.023 & 1.029 & 1.052 & 0.991 & 1.065 & 1.068 \\
\hline Guangxi & 0.998 & 1.058 & 1.056 & 0.995 & 1.042 & 1.037 & 0.992 & 1.072 & 1.063 \\
\hline Sichuan & 1.001 & 1.048 & 1.045 & 1.023 & 1.018 & 1.041 & 0.976 & 1.071 & 1.045 \\
\hline Guizhou & 0.995 & 1.060 & 1.054 & 1.010 & 1.037 & 1.048 & 0.975 & 1.085 & 1.051 \\
\hline Yunnan & 1.000 & 1.030 & 1.030 & 1.000 & 1.066 & 1.066 & 0.998 & 1.003 & 1.000 \\
\hline Shanxi & 1.007 & 1.045 & 1.053 & 1.028 & 1.018 & 1.046 & 0.992 & 1.073 & 1.061 \\
\hline Gansu & 1.007 & 1.044 & 1.050 & 1.020 & 1.015 & 1.036 & 0.993 & 1.068 & 1.068 \\
\hline Qinghai & 0.989 & 1.055 & 1.044 & 0.999 & 1.030 & 1.029 & 1.981 & 1.075 & 1.064 \\
\hline Ningxia & 1.000 & 1.052 & 1.052 & 1.025 & 1.023 & 1.049 & 0.981 & 1.072 & 1.059 \\
\hline Xinjiang & 1.007 & 1.039 & 1.047 & 1.041 & 1.017 & 1.058 & 0.976 & 1.054 & 1.037 \\
\hline $\begin{array}{c}\text { Eastern } \\
\text { region }\end{array}$ & 1.011 & 1.050 & 1.061 & 1.018 & 1.027 & 1.046 & 1.002 & 1.071 & 1.071 \\
\hline $\begin{array}{l}\text { Central } \\
\text { region }\end{array}$ & 1.005 & 1.049 & 1.052 & 1.008 & 1.030 & 1.039 & 1.005 & 1.069 & 1.064 \\
\hline $\begin{array}{l}\text { Western } \\
\text { region }\end{array}$ & 1.001 & 1.048 & 1.049 & 1.016 & 1.030 & 1.046 & 0.985 & 1.061 & 1.053 \\
\hline China & 1.004 & 1.049 & 1.054 & 1.015 & 1.029 & 1.044 & 0.997 & 1.060 & 1.062 \\
\hline
\end{tabular}


The above table shows that, from 1978 to 1990, the average TFP growth rate of eastern part is $6.1 \%$, the average TFP growth rate of central region is $5.2 \%$, while the average TFP growth rate of western region of $4.9 \%$. Clearly, the eastern region is higher than the other two regions and TFP growth has significant regional disparities. Details from the various provinces, the TFP growth rate of Jiangsu, Zhejiang and other eastern regions exceed 7.5\%, while Anhui, Yunnan, and Xinjiang are only 3\%. From 1978 to 1990, the TFP growth rate of eastern region was 4.6\%, the TFP growth rate of central region was $3.9 \%$, the TFP growth rate of western region was $4.6 \%$, TFP had no obvious regional disparities. From 1991 to 2012, there has been significant increased on the TFP growth rates, while regional disparities were arisen, TFP growth rate in eastern, central and western region was $7.1 \%, 6.4 \%$ and $5.3 \%$. TFP growth in Jiangsu, Fujian which lie in eastern region were more than $8.5 \%$, significantly higher than other mid-western cities. From a view of EC, since 1978, EC growth rate in eastern reigion was $1.1 \%$, however, in central region $0.5 \%$, and in western region $0.2 \%$. Changes in technical efficiency were small but there were significant regional disparities. From 1991 to 2012, EC in eastern region increased 0.2\%, in central region increased 0.5\%, in western region decreased $1.5 \%$. From the perspective of TC, TC played an important role on TFP growth. In the period of Chinese economic reform, from 1978 to 2012, 90\% of TFP increase was from TC. From 1991 to 2012, regional differences were more obviously, TC growth rates in eastern, central and western region were $7.1 \%, 6.9 \%$ and $6.1 \%$ respectively.

\section{Regression analysis for regional TFP convergence}

According to Barro and Sala-I-Mattin $(1992,1995,1997)$ analysis, we choose the absolute convergence $\beta$ regression model to check whether regional convergence happened. Regression model we set as follows:

$\Delta T F P_{i t}=\alpha+\beta \operatorname{InTFP} P_{i o}+\varepsilon_{i t}$

$\Delta T F P_{i t}$ is TFP growth rate from 0 to $t, \operatorname{InTFP}_{i 0}$ is TFP in $0, \varepsilon_{i t}$ is random disturbance term. If $\beta$ is less than 0 , it proved to be convergence, while if $\beta$ more than 0 , it proved to be divergent.

Use the data that processed and calculate by Eviews6.0, the regression equation is:

Table 2 Regression analysis

\begin{tabular}{|c|c|c|c|c|c|c|}
\hline & $\begin{array}{c}\text { Coefficie } \\
\mathrm{nt}\end{array}$ & T value & Adj-R & S.E. & $\mathrm{F}$ & $\mathrm{P}$ \\
\hline $\begin{array}{c}\text { Constant } \\
\text { term }\end{array}$ & 0.0514 & 75.05 & 0.0363 & 0.042 & 16.919 & 0.000 \\
\hline Ln TFP $_{\text {io }}$ & 0.2405 & 21.77 & & & & \\
\hline
\end{tabular}

Table 2 shows that $\mathrm{Ln} \mathrm{TFP}_{\mathrm{io}}=0.2405$, so we can get that $\beta$ is more than one, that is, TFPs are divergent.

It can be seen, from 1991 to 2012, although economic development was very rapid in China, there has a tendency that the disparity of TFP growth in various provinces has been expanded, reflecting wider economic growth gap existed. 


\section{Conclusions}

It can be seen from the above analysis, from 1978 to 2012, China's TFPs grew significantly. But after 1991, it showed a significant divergence characteristic that closely related to the country's stage of economic development. From 1991 to 2012, China's economy entered the stage of industrialization, urbanization, economy grew rapidly, and there was a strong economic competition among regional. while the provinces are quite different due to the natural resources in science and technology, production and technical conditions, under the conditions there were still some limitations of resources flowing in science and technology. The tendency of wider regional disparity was inevitable. And from the next period of time, due to our progressive economic system and the gradient regional policy, the gap of institutional changes among different regions will make the gap of regional economic development continues to expand.

\section{References}

[1] Fare R,Grosskopf S,Margaritis D.APEC and the Asian Economic Crisis: Early Signals from Productivity Trends. Asian Economic Journal. 2001

[2] Qiang Liu, The Convergence Analysis of Economic Growth in China , Journal of Economic Research , 2001 , NO.6.

[3] Weihua Liu , Estimate of Actual Total Factor Productivity in China During 1980-2004, Journal of Hebei University of Economics and Trade ， 2008 ， Vol.29 ， NO.2.

[4] Xiaoe Qu , China's Interprovincial Total Factor Energy Efficiency Change Decomposes , Research on Economic technology research 2009 , NO.8.

[5] Mei Wei , Influential Factors of Regional Total Factor Productivity and Efficient Convergence Analysis, Statistics and Decision, 2008, NO.12.

[6] Zhang Jun , Shi Shaohua , Total Factor Productivity Change in Chinese Economy During 1952-1998, Intersection of World Economy , 2003 , NO.2. 